\title{
The bile salt export pump
}

\author{
Bruno Stieger • Yvonne Meier • Peter J. Meier
}

Received: 15 June 2006 / Accepted: 8 August 2006 / Published online: 19 October 2006

(C) Springer-Verlag 2006

\begin{abstract}
Canalicular secretion of bile salts mediated by the bile salt export pump Bsep constitutes the major driving force for the generation of bile flow. Bsep is a member of the B-family of the super family of ATP-binding cassette transporters and is classified as ABCB11. Bsep has a narrow substrate specificity, which is largely restricted to bile salts. Bsep is extensively regulated at the transcriptional and posttranscriptional level, which directly modulates canalicular bile formation. Pathophysiological alterations of Bsep by either inherited mutations or acquired processes such as inhibition by drugs or disease-related down regulation may lead to a wide spectrum of mild to severe forms of liver disease. Furthermore, many genetic variants of Bsep are known, some of which potentially render individuals susceptible to acquired forms of liver disease.
\end{abstract}

Keywords Bile formation - Bile acid transport - ATP-binding cassette transporter $\cdot$ Mutation $\cdot$ Polymorphism

\section{Introduction}

Bile formation is one of the key functions of mammalian liver. It involves vectorial secretion of bile acids and other

B. Stieger $(\bowtie) \cdot$ Y. Meier

Department of Medicine, Institute of Clinical Pharmacology

and Toxicology, University Hospital,

8091 Zürich, Switzerland

e-mail: bstieger@kpt.unizh.ch

P. J. Meier

University of Basel,

Basel, Switzerland cholephilic compounds across hepatocytes from the sinusoidal blood plasma into bile canaliculi $[50,61,78,91]$ (Fig. 1). Thereby, bile acids or bile salts are concentrated more than 500-fold in bile as compared to blood plasma. This concentrative process is dependent on ATP [87] and mainly driven by the canalicular bile salt export pump BSEP [61]. BSEP is a member of the B-family of the ATBbinding cassette $(A B C)$ superfamily of transporters and is classified as ABCB11.

In 1995, a close relative to MDR1 (ABCB1 or Pglycoprotein) was identified in pig and was named as the sister of P-glycoprotein (spgp) [14]. In a panel of mRNAs from different rat tissues, only the liver was positive by Northern blotting. Based on the hypothesis that the canalicular bile salt export system should be a member of the ABCtransporter superfamily and predominantly, if not exclusively expressed in the liver, the rat isoform of spgp was cloned from liver. After its expression in insect Sf9 cells with the baculovirus system, it could be demonstrated that spgp represents an ATP-dependent bile salt transporter [33]. Based on its function, spgp was renamed as "bile salt export pump" or "Bsep". Positional cloning of the defective gene in patients with progressive familial intrahepatic cholestasis type 2 (PFIC2) led to the identification of the human BSEP gene [88], indicating that PFIC2 was actually a BSEP deficiency syndrome [78]. The selective absence of bile salts in the bile of all PFIC2 patients further confirmed the bile salt transport function of BSEP [45]. Bsep is evolutionary relatively old, and a Bsep orthologue is already present in skate (Raja erinacea) liver [10]. Furthermore, partial Bsep sequences have been described in the teleost winter flounder (Pseudopleuronectes americanus) [14]. Of note, ATP-dependent bile salt transport activity has also been demonstrated in plant vacuoles [42] and in yeast, where the responsible 


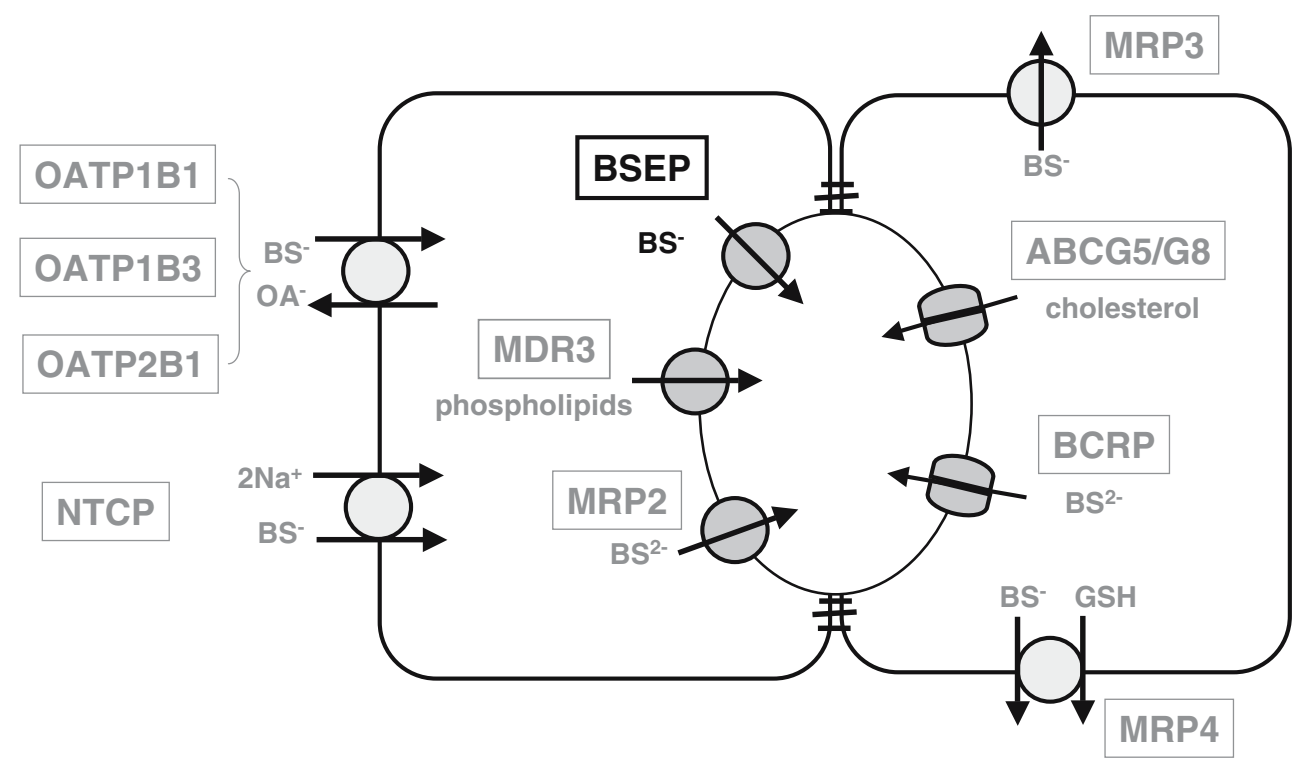

Fig. 1 Principle mechanisms of bile formation. Bile salts are taken up into hepatocytes in a sodium-dependent manner by the sodiumtaurocholate transporting polypeptide (NTCP) and, to a lesser extent, in a sodium-independent manner by the organic anion transporting polypeptides (OATPS) [61]. Bile salts are secreted across the canalicular plasma membrane by the bile salt export pump (BSEP), from where they promote in concert with the multidrug-resistance protein $3(M D R 3)$ the release of phospholipids from the canalicular plasma membrane (see article by Oude Elferink in this issue).

transport protein (BAT1) is also a member of the $\mathrm{ABC}$ transporter superfamily [74].

\section{Functional characteristics}

The BSEP gene is located on chromosomes $2 \mathrm{q} 24-31$ [88]. Its 28 exons encode a protein of 1,321 amino acids $[9,72]$. Rat and mouse Bsep consist of 1,321 amino acids and exhibit molecular weights of $160 \mathrm{kDa}[33,35,54,69]$. Based on comparison of the molecular weight of rat Bsep expressed in Sf9 cells in comparison to rat canalicular membrane vesicles, it is very likely that Bsep is a glycoprotein [33]. Extensive functional comparison in isolated rat canalicular plasma membrane vesicles and in Sf9 cell vesicles revealed similar kinetic properties of rat Bsep with $K_{\mathrm{m}}$ values of $2.1 \mu \mathrm{M}$ for taurocholate, $3.8 \mu \mathrm{M}$ for glycocholate, $3.6 \mu \mathrm{M}$ for taurochenodeoxycholate, and $6.2 \mu \mathrm{M}$ for tauroursodeoxycholate [86]. These findings indicate that expression in the Sf9 cell systems is suitable for functional characterization of various Bsep orthologues from different species. In fact, comparison of the intrinsic clearances of mouse, rat, and human Bsep/BSEP revealed the same rank order of transporter preferences for different bile salts and comparable $K_{\mathrm{m}}$ values [72]. These close functional relationships between Bsep of different species
Phospholipids form together with bile salt-mixed micelles, which act as a vehicle for cholesterol that is exported into the canaliculus by ABCG5/G8 (see article by Patel in this issue). In addition, multidrug resistance protein $2(M R P 2)$ and breast cancer resistance protein $(A B C G 2)$ mediate canalicular secretion of organic anions and divalent bile salts (see articles by Keppler and Sugiyama, respectively, in this issue). The basolateral exporters MRP3 and MRP4 may act as salvage systems to lower cytoplasmic levels of potentially hepatotoxic compounds (see article by Borst in this issue)

are paralleled by amino acid sequence similarities of more than $80 \%$, indicating that functional studies with rat Bsep in isolated canalicular liver plasma membrane vesicles can be extrapolated to human BSEP. In rats, the specificity of Bsep is restricted to monovalent bile salts, whereas no transport of taurolithosulfocholate, leukotriene C4, DNP-SG, estradiol-17 $\beta$-glucuronide, or GSSG was observed [86]. Recently, rat and human Bsep/BSEP were compared after expression in HEK293 cells and were found to have qualitative comparable transport properties with one exception: Human BSEP transported taurolithocholate 3-sulfate significantly, whereas virtually no transport was observed with rat Bsep [38]. This difference may reflect the fact that the human bile salt pool contains higher amounts of taurolithocholate 3-sulfate than the rodent bile salt pool. Despite the close structural relationship between bile salts to cholesterol, rat Bsep seems not to be able to transport sitosterol [2]. Nevertheless, the substrate specificity of Bsep/BSEP seems not to be entirely restricted to bile salts since transfection of the ovary cancer cell line SKOV3 with rat Bsep induced a slight resistance to taxol [15]. In addition, mouse Bsep expressed in LLC-PK 1 cells has been shown to mediate the transport of vinblastine and the fluorescent Mdr1 substrate calcein AM [54]. Interestingly, in vesicles isolated from transfected HEK 293 cells, ATPdependent pravastatin transport could be demonstrated for 
both rat Bsep and human BSEP [40]. Hence, although monovalent bile salts represent the predominant transport substrate class for all Bsep isoforms, some additional compounds may also be transported by Bsep/BSEP. Nevertheless, the fact that the absence of functional BSEP in the canalicular membrane due to mutations in the $B S E P$ gene leads to severe forms of intrahepatic cholestasis in childhood and to bile salt levels $<1 \%$ of normal in bile supports the concept that the major physiological role of the bile salt export pump is ATP-dependent bile salt transport [45].

\section{Tissue distribution}

The partial sequence of Bsep from pigs was used by Childs and coworkers to determine its tissue distribution by Northern blotting. These data revealed a predominant, if not exclusive, expression of pig Bsep in the liver [14]. This tissue distribution was confirmed after a full-length sequencing of Bsep in the rat [33] and in mouse [35, 54]. However, using a PCR-based approach, Bsep mRNA was also identified in brain cortex and small and large intestine in the rat [90]. Based on a real-time PCR approach, expression of BSEP was not only found in human liver but also at very high levels in human testis, an organ which had not been previously investigated for BSEP expression [53]. The same study detected some BSEP mRNA also in several other tissues. The observed predominant expression of Bsep in the liver is preserved during evolution since in the primitive elasmobranch vertebrate, little skate, Bsep is exclusively expressed in the liver [10].

\section{Ontogenesis and regulation}

Ontogenesis of Bsep has been most extensively studied in rat liver. Bsep mRNA could be detected at day 15 in developing mouse liver [54] and, although at low levels, at embryonic day 20 in rat liver [30, 89, 104]. In rats, positive canalicular protein expression is observed at low levels at embryonic day 20. After embryonic day 20, the expression of rat Bsep at the protein and mRNA levels rapidly increases up to almost adult levels within the first week after birth [30, 89, 104]. This sequence of expression coincides well with the development of the major bile salt uptake system Ntcp in rat liver as well as with the development of the enterohepatic circulation of bile salts [30]. In humans, the BSEP gene is expressed at midgestation at mRNA levels much lower than in the adult liver [13]. Immunohistochemical analysis demonstrated BSEP expression in the fetal liver both at the bile canaliculi and within hepatocytes.
Regulation of Bsep occurs at two main levels: first, at the transcriptional level and, second, at the posttranscriptional level by insertion and retrieval of Bsep into the canalicular plasma membrane and/or posttranslational protein modifications. The latter two mechanisms can act at very short-time scales, whereas regulation at the transcriptional level has a more long-term impact.

Transcriptional regulation of Bsep The predominant transcription factor involved in the transcriptional regulation of Bsep expression is the farnesoid X receptor (FXR) [23, 50]. This transcription factor acts as an intracellular bile salt sensor in hepatocytes and, upon activation by bile salts, binds as a heterodimer with retinoid $\mathrm{X}$ receptor (RXR) to the Bsep promoter. This leads to an upregulation of Bsep expression and consequently to increased canalicular bile salt secretion [3, 32]. These data are supported by a reduced expression of Bsep in mice lacking the gene for FXR [85]. This regulatory mechanism seems to be more strongly affected by transhepatocellular bile salt flux than by steady-state bile salt levels [102]. Since intracellular bile salts are elevated in cholestatic liver disease, this regulatory pathway represents an important protective mechanism for hepatocytes [23]. Recently, it has been shown that the vitamin D receptor (VDR) directly interacts with FXR and, upon binding of vitamin D3, inhibits FXR-mediated transactivation of $B S E P$ [41]. In primary cultured rat hepatocytes, mRNA and Bsep protein levels are partially maintained for approximately $72 \mathrm{~h}$ of culture time [82]. Interestingly, hyperosmolarity of the culture medium leads to upregulation and hypoosmolarity to downregulation of Bsep mRNA expression [100]. Furthermore, maintenance of Bsep mRNA expression was reported to be critically dependent on the presence of dexamethasone in the culture medium [100]. However, in other studies using sandwich cultured primary rat hepatocytes, the expression of Bsep on both the mRNA and protein levels was less sensitive to the presence of dexamethasone [57, 92], although very low dexamethasone concentration influenced Bsep expression levels also in primary hepatocytes cultured in a collagen-sandwich configuration [92]. Taken together, these results indicate that not only the bile acid sensor FXR is crucial for the control of Bsep expression, but more complex regulatory cascades involving for example steroid receptors need to be considered as well. This is supported by the observation that patients with biliary atresia improve their bile flow rate after surgery with high-dose steroid treatment [64].

Short-term posttranscriptional regulation of Bsep There is considerable evidence from animal models that the canalicular localization of Bsep can be regulated by endo- and 
exocytotic mechanisms $[4,96]$. Studies in isolated perfused rat livers showed a stimulation of biliary excretion of bile salts concomitant with a stimulation of vesicular transport processes in hepatocytes [36]. Similar experiments in isolated rat hepatocyte couplets resulted in an enhanced secretion of a fluorescent bile acid derivative into the canalicular vacuole [8]. This stimulation of bile salt secretion is independent from protein synthesis but sensitive to the microtubule disrupting agent colchicine, suggesting the presence of an intracellular regulatory pool of Bsep transporters. Treatment of rats with intravenous taurochcholate or dibutyryl cAMP resulted in a fast increase in functional Bsep insertion into canalicular plasma membranes [31]. Inhibition of this process by colchicine confirmed the postulated presence of an intracellular vesicular pool of Bsep, which upon stimulation is incorporated into the canalicular plasma membrane in a microtubule-dependent process. In addition, cAMP-dependent Bsep incorporation into the canalicular plasma membrane was inhibited by wortmannin indicating an important role of PI 3-kinase [66]. These regulatory mechanisms are independent from protein biosynthesis and hence relate to posttranscriptional events. In isolated rat canalicular plasma membrane vesicles, products of PI 3-kinase action exerted a direct effect on the transport activity of Bsep, indicating that PI 3-kinase modulates bile salt transport activity both by Bsep density and Bsep activity in the canalicular plasma membrane [65]. Biosynthetic studies indicate a direct targeting of Bsep from the Golgi to the canalicular plasma membrane. Furthermore, treating rats simultaneously with cAMP and with taurocholate resulted in additive incorporation of Bsep into the canalicular membrane to levels higher than with a single modulator. Based on all these observations, it has been postulated that two separate intracellular pools exist within hepatocytes, from which Bsep can be recruited and inserted into the canalicular plasma membrane under the conditions of increased bile flow rates [47]. In addition to these pathways, the mitogenactivated kinase cascades are also involved in the posttranscriptional regulation of Bsep expression: Induction of choleresis by tauroursodeoxycholic acid or alteration of bile flow by anisosomolarity leads to canalicular insertion/ retrieval of Bsep, a process that is critically dependent on mitogen-activated kinases [83]. In addition, studies in polarized cell lines expressing Bsep revealed that HAX-1 and myosin II regulatory light chain are required for the trafficking of Bsep to the apical membrane as well as in the regulation of its abundance in the apical plasma membrane of MDCK cells [12, 73]. Studies in the polarized hepatic WIF-B9 cell line indicated that Bsep undergoes a constitutive cycling between a rab11 positive compartment and the canalicular plasma membrane domain [95]. Bsep and, hence, the capacity of canalicuar bile salt secretion may be regulated not only via carrier density in the canalicular plasma membrane but also by posttranslational modifications of the Bsep protein. Mouse Bsep, if coexpressed with the $\alpha$-isoform of protein kinase $\mathrm{C}$ in $\mathrm{Sf} 9$ cells, is phosphorylated, which could affect the functional properties of Bsep [69, 71]. Posttranslational processes occur on short-time scales may be needed to adapt canalicular bile salt secretion to a short-term increase in hepatocellular bile salt load, such as, for example, in a postprandial state. In contrast, the half-life of Bsep in rats is 4 to 6 days, which is in line with the half-life of other rat hepatocellular plasma membrane proteins [48]. To our knowledge, factors regulating the half-life of Bsep have not yet been investigated. Such events may, however, turn out to be important in chronic alterations of liver functions, such as various forms of liver disease.

\section{Pathophysiological consequences of altered Bsep function and expression}

Inhibition of Bsep/BSEP leads to a reduced bile salt secretion and decreased bile flow, a process called cholestasis. This has been shown in the perfused rat liver, for example, for cyclosporine A [6]. After the cloning of rat Bsep, it was possible to directly test the inhibition of Bsep expressed in $\mathrm{Sf} 9$ cells in the absence of other organic anion transporters. These studies showed that cyclosporine A as well as glybenclamide, rifampicin, and rifamycin are competitive inhibitors of Bsep [86]. The same drugs also inhibit human BSEP $[9,72]$. Other drugs that have been shown to inhibit BSEP are bosentan [25], troglitazone [29], and fluvastatin (C. Lang, Y. Meier, and C. Pauli-Magnus, submitted for publication). Such drugs may, in susceptible humans, cause acquired cholestasis, which rapidly resolves after the withdrawal of the drug. Alteration of Bsepmediated bile salt secretion can also be caused indirectly. For example, the Bsep inhibitor bosentan leads to a hypercholeresis in rats, which depends on the canalicular presence of functional Mrp2 [28]. This canalicular hypercholeresis may lower the bile salt concentration in the canalicular lumen and consequently reduce canalicular lipid secretion [28]. Such a mechanism could in turn lead, via secondary inhibition of Bsep, to the observed accumulation of serum bile acids in rats after administration of bosentan $[25,60]$. Studies with mouse Bsep demonstrated that some drugs inhibit not only the transport activity of Bsep but also its ATPase activity [69]. Since the substrate binding site(s) of the various Bsep isoforms is unknown at present, it cannot be excluded that inhibitory drugs are also potential transport substrates of Bsep. Very interestingly, estradiol-17 $\beta$-glucuronide, a cholestat- 
ic metabolite of estrogen, requires coexpression of Mrps for inhibition of Bsep $[1,86]$. This has been interpreted as so-called trans-inhibition since estradiol-17 $\beta$-glucucronide needs to be transported into the canalicular lumen before it can exert its cholestatic action on Bsep. Most importantly, this result has been confirmed for progesterone-sulfate, a key metabolite that increases during pregnancy [93].

Although inhibition of Bsep by drugs and other substances is rapid and reversible, other pathophysiological situations are associated with more pronounced effects on Bsep expression. Sepsis in patients with gram-negative infections may be associated with cholestasis [67]. The causative agent for induction is the endotoxin lipopolysaccharide secreted by gram-negative bacteria. In experimental septic models, Bsep mRNA and protein levels were reduced [55, 94]. In addition, such models of sepsis have provided evidence for a relocation of canalicular Bsep to a percicanalicular vesicular compartment [7, 103]. These effects on Bsep expression could be prevented with the osmolyte taurine [68]. Treatment of human liver slices with lipopolysaccharide also induced the downregulation of BSEP at the protein level, suggesting similar mechanisms in human liver as in animal models [22].

Obstructive cholestasis or cholestasis induced by ethinylestradiol treatment of rats leads to a modest reduction in the expression of Bsep in the canalicular membrane [55] and thus resembles the moderate downregulation of Bsep in primary cultured rat hepatocytes [82]. In the rat model of cholestasis associated with pregnancy (treatment of rats with estradiol), a relocation of Bsep into subapical vesicles is observed [18]. If these rats are treated with 6-ethyl chenodeoxycholate, a potent ligand for FXR, Bsep is induced and the cholestasis induced by estradiol is reversed [27]. And finally, treatment of rats with the cholestatic bile acids lithocholate or taurolithocholate leads to a retrieval of Bsep from the canalicular plasma membrane [19], which can be prevented by the administration of cAMP [19], silibinin [17], or tauroursodeoxy cholic acid [21].

In patients with obstructive cholestasis who underwent biliary drainage, BSEP mRNA levels were reduced in individuals with poor drainage as compared to controls. Additionally, BSEP staining appeared fuzzy, indicating altered expression as a consequence of cholestasis [84]. Another cholestatic liver disease is primary biliary cirrhosis. In such patients, the expression of BSEP is preserved in contrast to the basolateral uptake systems $[105,106]$. Patients with inflammation-induced icteric cholestasis due to alcoholic hepatitis have a reduced expression of BSEP mRNA and protein [106]. Frequently, cholestatic liver disease is treated with ursodeoxycholic acid $[5,79]$. In a recent study, it was observed that treatment of patients with ursodeoxycholic acid leads to a stimulation of BSEP expression [59]. Additionally, after liver transplantation, the bile flow rate is initially low and recovers with time. This recovery of bile flow rate is paralleled by an increased expression of BSEP mRNA in liver biopsies from transplanted livers [34].

\section{Genetics}

Mutations in canalicular transporter genes and in particular in the BSEP gene that lead to hereditary forms of liver disease are well known. The BSEP deficiency syndrome is caused by mutations in the BSEP gene and leads to functional defects of BSEP-mediated canalicular bile salt secretion [78]. Depending on the clinical course of this syndrome, two different clinical entities of the BSEP deficiency syndrome are known: a mild form also called benign recurrent intrahepatic cholestasis type 2 (BRIC2) and a severe form also called progressive familial intrahepatic cholestasis type 2 (PFIC2). These two diseases represent a heterogeneous group of cholestatic conditions, and BRIC 2 may develop into PFIC2 [51,78]. So far, more than 30 mutations in the BSEP gene have been identified in patients with BSEP deficiency syndrome [78] (Fig. 2). The majority of these mutations affect evolutionary conserved amino acid residues, and the affected amino acids tend to be located in the large cytoplasmic loops of BSEP. In many patients with severe BSEP deficiency syndrome, BSEP staining was absent on liver sections [45, 46]. Direct investigation of the functional consequences of the BSEP mutations in human liver is impossible. Therefore, studies using heterologous expression systems of mutated forms of BSEP were used to subsidize for this lack of in vivo data. Expression of various BSEP mutations affecting conserved amino acids in a rat or mouse background in polarized cells such as MDCK or HepG2 cells has resulted in defects of apical trafficking and/or functional impairment of BSEP as well as in temperature-sensitive, unstable forms of BSEP $[81,97]$. It should, however, be noted that such studies on the functional impact of the human mutations based on heterologous expression systems may lead to conflicting results suggesting species-specific effects on transport function [81, 97]. Therefore, directly testing the human mutated forms of BSEP in vivo seems to be an important prerequisite to obtain insights into the functional consequences of BSEP mutations [37, 70].

Although inherited mutations in the BSEP gene are very rare [75, 77], acquired forms of cholestasis such as, for example, primary biliary cirrhosis, primary sclerosing cholangitis, cholestasis associated with pregnancy, or drug-induced cholestasis are more frequent [62, 77]. A recent genetic screen of patients identified three nonsynonymous $A B C B 11$ variants to be specifically associated 


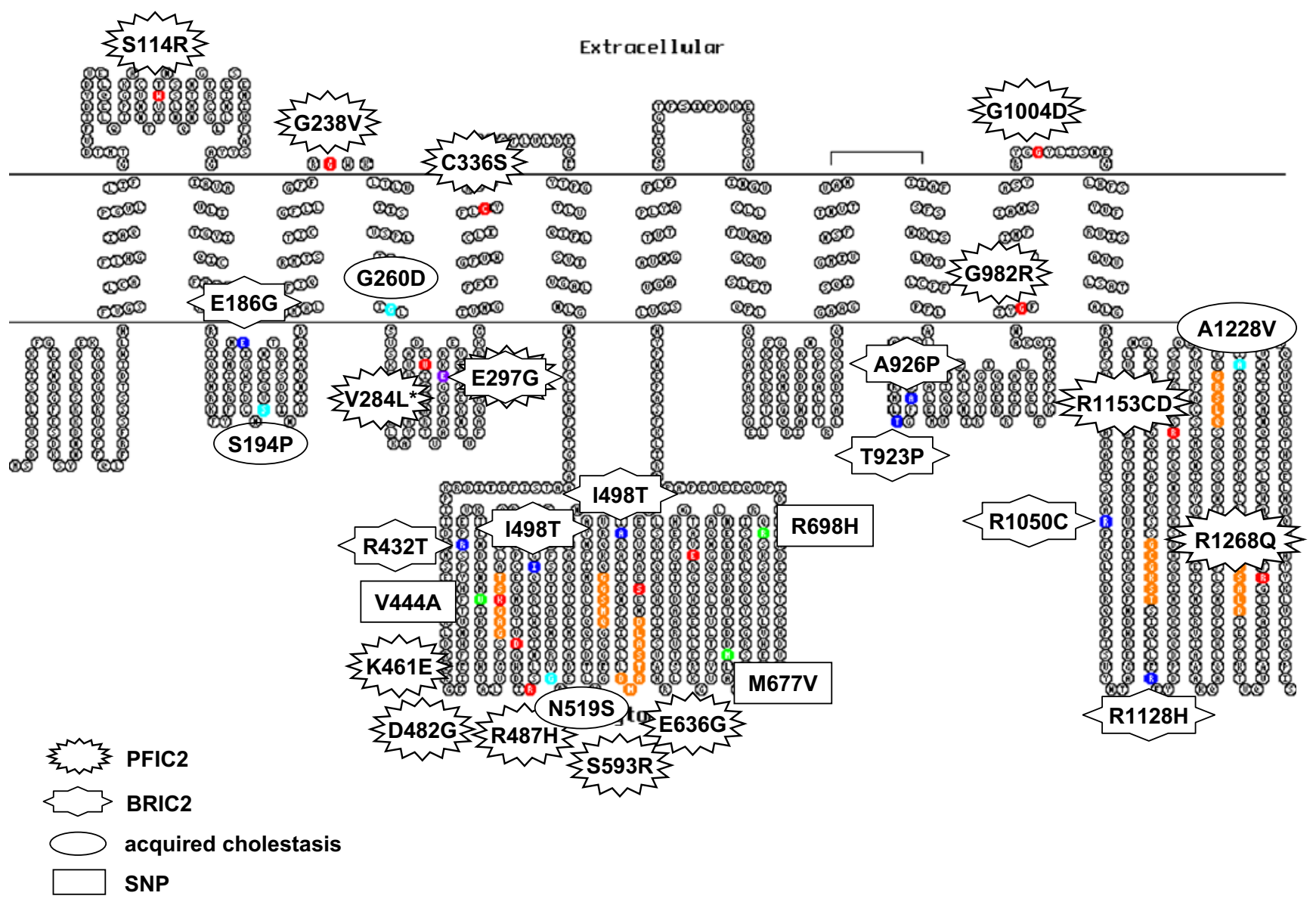

Fig. 2 Putative secondary structure of Bsep (NT-005403) generated with the TOPO program (http://www.sacs.ucsf.edu/TOPO-run/wtopo.pl). Walker A motif, family signature, and Walker B motif [20] are shown in orange. Genetic variants and mutations (taken from [51, 78]) are represented as green for single nucleotide polymorphisms $(S N P)$, red for mutations identified in patients with progressive familial intrahepatic cholestasis type 2 (PFIC1), and blue for mutations identified in patients with benign recurrent intrahepatic cholestasis type 2 (BRIC2). purple E297G was found in PFIC2 and BRIC2 patients, respectively. Amino acids highlighted in cyan were associated acquired forms of cholestasis including intrahepatic cholestasis of pregnancy, primary sclerosing cholangitis, and primary biliary cirrhosis. $\left(^{*}\right)$ The mutation V284L was found in a patient with PFIC2, whereas the SNP V284A occurs in healthy individuals with primary biliary cirrhosis and primary sclerosing cholangitis [76]. In cholestasis associated with pregnancy, the situation seems to be controversial [24, 78]. Consequences of such variants potentially include altered expression and or altered function of BSEP.

Cholestasis induced by BSEP inhibition, for example, by drugs, is a rare event observed in patients. Hence, there need to be underlying mechanisms rendering such patients susceptible to BSEP inhibition. A strong candidate is the genetic background. Recently, the variation of BSEP protein expression levels was studied in 110 healthy liver specimens by Western blotting [63]. BSEP expression levels of these individuals were found to display a unimodal distribution and showed no correlation with, for example, sex or medication. Importantly, $17 \%$ of the individuals were found to have a low or very low expression level. In these individuals, low BSEP expression level was found to be associated with the nonsynonymous $1457 \mathrm{C}$ allele (444A) of $A B C B 11$. Individuals with low or very low expression levels of BSEP could be at risk of developing acquired forms of cholestasis, for example, by drugs or pregnancy.

\section{Mice with genetically altered Bsep expression}

In contrast to humans, functional inactivation of the Bsep gene (also called sister of P-glycoprotein gene, spgp) does not lead to a severe, progressive cholestasis in mice [99]. Although the knockout animals are viable and fertile, they present with mild growth retardation. Knockout animals have no abnormalities in their serum liver parameters. Their bile flow rate is slightly but not significantly lower in comparison to controls, but the total bile salt output into bile is massively reduced and their liver bile salt concen- 
trations are increased accordingly. Biliary secretion of cholate and its conjugates is $6 \%$ of normal, supporting the key role of Bsep in canalicular taurocholate secretion. Most interestingly, these knockout mice secrete a novel tetrahydroxylated bile acid into bile [80]. The Bsep knockout animals have substantial increases of malondialdehyde levels in brain and heart, indicating an increased lipid peroxidation as a consequence of elevated serum bile acid levels [56]. If Bsep knockout animals are fed with a diet containing cholate, they become severely cholestatic and have a high mortality rate, which is more pronounced in males than females [98]. Unexpectedly, cholate-fed knockout mice secrete significant amounts of cholate conjugate into bile, indicating a salvage transport system for canalicular bile salt secretion. Comparative analysis of gene expression profiles in control and knockout-mice after cholate feeding revealed a striking upregulation of Mdrla [98]. This observation may indicate that mouse Mdrla could act as a salvage transporter for bile salts in conditions of high intracellular bile salt concentration. Transport studies using canalicular plasma membrane vesicles from Bsep knockout animals revealed a residual ATP-dependent transport activity for taurocholate [52]. Plasma membrane vesicles isolated from a drug-resistant Chinese hamster ovary cell line expressing high levels (about $15 \%$ of total plasma membrane proteins) of class I P-glycoprotein also exhibit ATP-dependent bile salt transport, albeit with lower affinity than Bsep [52]. Hence, Mdr1 may act as a salvage system for bile salts in case of nonfunctional or impaired Bsep. Since the affinity of Mdr1 for bile salts is much lower, intracellular bile salts may rise to toxic levels in hepatocytes and cause liver injury (see article by V. Ling, this issue). The situation in patients with PFIC2 may differ to some extent from the knockout animals since analysis of four PFIC2 patients showed no significant upregulation of MDR1 mRNA [46].

Overexpression of Bsep in the liver transgenic animals leads to an increased biliary bile salt output concomitant with an increase in bile flow rate and biliary lipid secretion [26]. Fecal loss of bile salts is normal in these animals. If these mice are fed a lithogenic diet, they have a markedly reduced hepatic steatosis in comparison to controls. These findings highlight the role of Bsep in the maintenance of hepatocellular lipid homeostasis.

\section{Outlook}

The gene for the bile salt export pump Bsep was initially identified as a close relative of the gene encoding Pglycoprotein. Bsep was subsequently shown to be an ATPdriven bile salt pump located to the canalicular plasma membrane of hepatocytes. In this strategic position, Bsep is a key transporter involved in canalicular bile formation and constitutes the main driving force for enterohepatic circulation of bile salts. The regulation of Bsep is set up such that bile salt concentrations in hepatocytes are kept constant at low levels. On the basis that elevated bile salt concentrations are toxic to hepatocytes [49], Bsep may act as a "vacuum cleaner" [39] for bile salts in hepatocytes. Proper function of Bsep is critical for maintaining bile salt concentration in systemic circulation in a tight range at low levels. In the light of recent findings that bile saltmediated FXR signaling controls liver regeneration and may even control liver size [44], Bsep may move up to a key protein controlling many vital processes in liver. Furthermore, evidence that the bile acid sensor FXR is controlling glucose and lipid metabolism is rapidly accumulating $[11,16,58]$. Since FXR requires bile salt binding to act to control expression target genes, Bsep may, by controlling bile salt concentration in systemic circulation, become an important control element in body energy and lipid homeostasis. And finally, bile salts have recently been shown to control energy expenditure by controlling intracellular thyroid hormone action by binding to the $\mathrm{G}$ protein-coupled receptor TGR5 [43, 101].

Acknowledgement This study was supported by grants \#31-64140.00 and 3100AO112524/1 from the Swiss National Science Foundation.

\section{References}

1. Akita H, Suzuki H, Ito K, Kinoshita S, Sato N, Takikawa H, Sugiyama Y (2001) Characterization of bile acid transport mediated by multidrug resistance associated protein 2 and bile salt export pump. Biochim Biophys Acta 1511:7-16

2. Albrecht C, Elliott JI, Sardini A, Litman T, Stieger B, Meier PJ, Higgins CF (2002) Functional analysis of candidate ABC transporter proteins for sitosterol transport. Biochim Biophys Acta 1567:133-142

3. Ananthanarayanan M, Balasubramanian N, Makishima M, Mangelsdorf DJ, Suchy FJ (2001) Human bile salt export pump promoter is transactivated by the farnesoid $\mathrm{X}$ receptor/bile acid receptor. J Biol Chem 276:28857-28865

4. Anwer MS (2004) Cellular regulation of hepatic bile acid transport in health and cholestasis. Hepatology 39:581-590

5. Beuers U (2006) Drug Insight: mechanisms and sites of action of ursodeoxycholic acid in cholestasis. Nat Clin Pract Gastroenterol Hepatol 3:318-328

6. Bohme M, Muller M, Leier I, Jedlitschky G, Keppler D (1994) Cholestasis caused by inhibition of the adenosine triphosphatedependent bile salt transport in rat liver. Gastroenterology 107:255-265

7. Bolder U, Jeschke MG, Landmann L, Wolf F, de Sousa C, Schlitt HJ, Przkora R (2006) Heat stress enhances recovery of hepatocyte bile acid and organic anion transporters in endotoxemic rats by multiple mechanisms. Cell Stress Chaperones 11:89-100

8. Boyer JL, Soroka CJ (1995) Vesicle targeting to the apical domain regulates bile excretory function in isolated rat hepatocyte couplets. Gastroenterology 109:1600-1611 
9. Byrne JA, Strautnieks SS, Mieli-Vergani G, Higgins CF, Linton KJ, Thompson RJ (2002) The human bile salt export pump: characterization of substrate specificity and identification of inhibitors. Gastroenterology 123:1649-1658

10. Cai SY, Wang L, Ballatori N, Boyer JL (2001) Bile salt export pump is highly conserved during vertebrate evolution and its expression is inhibited by PFIC type II mutations. Am J Physiol Gastrointest Liver Physiol 281:G316-G322

11. Cariou B, van Harmelen K, Duran-Sandoval D, van Dijk TH, Grefhorst A, Abdelkarim M, Caron S, Torpier G, Fruchart JC, Gonzalez FJ, Kuipers F, Staels B (2006) The farnesoid X receptor modulates adiposity and peripheral insulin sensitivity in mice. J Biol Chem 281:11039-11049

12. Chan W, Calderon G, Swift AL, Moseley J, Li S, Hosoya H, Arias IM, Ortiz DF (2005) Myosin II regulatory light chain is required for trafficking of bile salt export protein to the apical membrane in Madin-Darby canine kidney cells. J Biol Chem 280:23741-23747

13. Chen HL, Liu YJ, Feng CH, Wu CY, Shyu MK, Yuan RH, Chang MH (2005) Developmental expression of canalicular transporter genes in human liver. J Hepatol 43:472-477

14. Childs S, Yeh RL, Georges E, Ling V (1995) Identification of a sister gene to P-glycoprotein. Cancer Res 55:2029-2034

15. Childs S, Yeh RL, Hui D, Ling V (1998) Taxol resistance mediated by transfection of the liver-specific sister gene of P-glycoprotein. Cancer Res 58:4160-4167

16. Claudel T, Staels B, Kuipers F (2005) The Farnesoid X receptor: a molecular link between bile acid and lipid and glucose metabolism. Arterioscler Thromb Vasc Biol 25:2020-2030

17. Crocenzi FA, Basiglio CL, Perez LM, Portesio MS, Pozzi EJ, Roma MG (2005) Silibinin prevents cholestasis-associated retrieval of the bile salt export pump, Bsep, in isolated rat hepatocyte couplets: possible involvement of cAMP. Biochem Pharmacol 69:1113-1120

18. Crocenzi FA, Mottino AD, Cao J, Veggi LM, Pozzi EJ, Vore M, Coleman R, Roma MG (2003) Estradiol-17beta-D-glucuronide induces endocytic internalization of Bsep in rats. Am J Physiol Gastrointest Liver Physiol 285:G449-G459

19. Crocenzi FA, Mottino AD, Sanchez Pozzi EJ, Pellegrino JM, Rodriguez Garay EA, Milkiewicz P, Vore M, Coleman R, Roma MG (2003) Impaired localisation and transport function of canalicular Bsep in taurolithocholate induced cholestasis in the rat. Gut 52:1170-1177

20. Dean M, Rzhetsky A, Allikmets R (2001) The human ATPbinding cassette (ABC) transporter superfamily. Genome Res 11:1156-1166

21. Dombrowski F, Stieger B, Beuers U (2006) Tauroursodeoxycholic acid inserts the bile salt export pump into canalicular membranes of cholestatic rat liver. Lab Invest 86:166-174

22. Elferink MG, Olinga P, Draaisma AL, Merema MT, Faber KN, Slooff MJ, Meijer DK, Groothuis GM (2004) LPS-induced downregulation of MRP2 and BSEP in human liver is due to a posttranscriptional process. Am J Physiol Gastrointest Liver Physiol 287:G1008-G1016

23. Eloranta JJ, Kullak-Ublick GA (2005) Coordinate transcriptional regulation of bile acid homeostasis and drug metabolism. Arch Biochem Biophys 433:397-412

24. Eloranta ML, Hakli T, Hiltunen M, Helisalmi S, Punnonen $\mathrm{K}$, Heinonen S (2003) Association of single nucleotide polymorphisms of the bile salt export pump gene with intrahepatic cholestasis of pregnancy. Scand J Gastroenterol 38:648-652

25. Fattinger K, Funk C, Pantze M, Weber C, Reichen J, Stieger B, Meier PJ (2001) The endothelin antagonist bosentan inhibits the canalicular bile salt export pump: a potential mechanism for hepatic adverse reactions. Clin Pharmacol Ther 69:223-231
26. Figge A, Lammert F, Paigen B, Henkel A, Matern S, Korstanje R, Shneider BL, Chen F, Stoltenberg E, Spatz K, Hoda F, Cohen DE, Green RM (2004) Hepatic overexpression of murine Abcb11 increases hepatobiliary lipid secretion and reduces hepatic steatosis. J Biol Chem 279:2790-2799

27. Fiorucci S, Clerici C, Antonelli E, Orlandi S, Goodwin B, Sadeghpour BM, Sabatino G, Russo G, Castellani D, Willson TM, Pruzanski M, Pellicciari R, Morelli A (2005) Protective effects of 6-ethyl chenodeoxycholic acid, a farnesoid X receptor ligand, in estrogen-induced cholestasis. J Pharmacol Exp Ther 313:604-612

28. Fouassier L, Kinnman N, Lefevre G, Lasnier E, Rey C, Poupon R, Elferink RP, Housset C (2002) Contribution of mrp2 in alterations of canalicular bile formation by the endothelin antagonist bosentan. J Hepatol 37:184-191

29. Funk C, Ponelle C, Scheuermann G, Pantze M (2001) Cholestatic potential of troglitazone as a possible factor contributing to troglitazone-induced hepatotoxicity: in vivo and in vitro interaction at the canalicular bile salt export pump (Bsep) in the rat. Mol Pharmacol 59:627-635

30. Gao B, St Pierre MV, Stieger B, Meier PJ (2004) Differential expression of bile salt and organic anion transporters in developing rat liver. J Hepatol 41:201-208

31. Gatmaitan ZC, Nies AT, Arias IM (1997) Regulation and translocation of ATP-dependent apical membrane proteins in rat liver. Am J Physiol Gastrointest Liver Physiol 272:G1041-G1049

32. Gerloff T, Geier A, Roots I, Meier PJ, Gartung C (2002) Functional analysis of the rat bile salt export pump gene promoter. Eur J Biochem 269:3495-3503

33. Gerloff T, Stieger B, Hagenbuch B, Madon J, Landmann L, Roth J, Hofmann AF, Meier PJ (1998) The sister of P-glycoprotein represents the canalicular bile salt export pump of mammalian liver. J Biol Chem 273:10046-10050

34. Geuken E, Visser D, Kuipers F, Blokzij1 H, Leuvenink HG, de Jong KP, Peeters PM, Jansen PL, Slooff MJ, Gouw AS, Porte RJ (2004) Rapid increase of bile salt secretion is associated with bile duct injury after human liver transplantation. J Hepatol 41:1017-1025

35. Green RM, Hoda F, Ward KL (2000) Molecular cloning and characterization of the murine bile salt export pump. Gene 241:117-123

36. Hayakawa T, Bruck R, Ng OC, Boyer JL (1990) DBcAMP stimulates vesicle transport and HRP excretion in isolated perfused rat liver. Am J Physiol Gastrointest Liver Physiol 259: G727-G735

37. Hayashi H, Takada T, Suzuki H, Akita H, Sugiyama Y (2005) Two common PFIC2 mutations are associated with the impaired membrane trafficking of BSEP/ABCB11. Hepatology 41:916-924

38. Hayashi H, Takada T, Suzuki H, Onuki R, Hofmann AF, Sugiyama Y (2005) Transport by vesicles of glycine- and taurine-conjugated bile salts and taurolithocholate 3-sulfate: a comparison of human BSEP with rat Bsep. Biochim Biophys Acta 1738:54-62

39. Higgins CF, Gottesman MM (1992) Is the multidrug transporter a flippase? Trends Biochem Sci 17:18-21

40. Hirano M, Maeda K, Hayashi H, Kusuhara H, Sugiyama Y (2005) Bile salt export pump (BSEP/ABCB11) can transport a nonbile acid substrate, pravastatin. J Pharmacol Exp Ther 314:876-882

41. Honjo Y, Sasaki S, Kobayashi Y, Misawa H, Nakamura H (2006) 1,25-Dihydroxyvitamin D3 and its receptor inhibit the chenodeoxycholic acid-dependent transactivation by farnesoid $\mathrm{X}$ receptor. J Endocrinol 188:635-643

42. Hortensteiner S, Vogt E, Hagenbuch B, Meier PJ, Amrhein N, Martinoia E (1993) Direct energization of bile acid transport into plant vacuoles. J Biol Chem 268:18446-18449 
43. Houten SM, Watanabe M, Auwerx J (2006) Endocrine functions of bile acids. EMBO J 25:1419-1425

44. Huang W, Ma K, Zhang J, Qatanani M, Cuvillier J, Liu J, Dong B, Huang X, Moore DD (2006) Nuclear receptor-dependent bile acid signaling is required for normal liver regeneration. Science 312:233-236

45. Jansen PLM, Strautnieks SS, Jacquemin E, Hadchouel M, Sokal EM, Hooiveld GJ, Koning JH, De Jager Krikken A, Kuipers F, Stellaard F, Bijleveld CM, Gouw A, Van Goor H, Thompson RJ, Muller M (1999) Hepatocanalicular bile salt export pump deficiency in patients with progressive familial intrahepatic cholestasis. Gastroenterology 117:1370-1379

46. Keitel V, Burdelski M, Warskulat U, Kuhlkamp T, Keppler D, Haussinger D, Kubitz R (2005) Expression and localization of hepatobiliary transport proteins in progressive familial intrahepatic cholestasis. Hepatology 41:1160-1172

47. Kipp H, Arias IM (2002) Trafficking of canalicular ABC transporters in hepatocytes. Annu Rev Physiol 64:595-608

48. Kipp H, Pichetshote N, Arias IM (2001) Transporters on demand: intrahepatic pools of canalicular ATP binding cassette transporters in rat liver. J Biol Chem 276:7218-7224

49. Krahenbuhl S, Talos C, Fischer S, Reichen J (1994) Toxicity of bile acids on the electron transport chain of isolated rat liver mitochondria. Hepatology 19:471-479

50. Kullak-Ublick GA, Stieger B, Meier PJ (2004) Enterohepatic bile salt transporters in normal physiology and liver disease. Gastroenterology 126:322-342

51. Lam CW, Cheung KM, Tsui MS, Yan MS, Lee CY, Tong SF (2006) A patient with novel ABCB11 gene mutations with phenotypic transition between BRIC2 and PFIC2. J Hepatol 44:240-242

52. Lam P, Wang R, Ling V (2005) Bile acid transport in sister of Pglycoprotein (ABCB11) knockout mice. Biochemistry 44:12598-12605

53. Langmann T, Mauerer R, Zahn A, Moehle C, Probst M, Stremmel W, Schmitz G (2003) Real-time reverse transcriptionPCR expression profiling of the complete human ATP-binding cassette transporter superfamily in various tissues. Clin Chem 49:230-238

54. Lecureur V, Sun D, Hargrove P, Schuetz EG, Kim RB, Lan LB, Schuetz JD (2000) Cloning and expression of murine sister of Pglycoprotein reveals a more discriminating transporter than MDR1/P-glycoprotein. Mol Pharmacol 57:24-35

55. Lee JM, Trauner M, Soroka CJ, Stieger B, Meier PJ, Boyer JL (2000) Expression of the bile salt export pump is maintained after chronic cholestasis in the rat. Gastroenterology 118:163172

56. Ljubuncic P, Yousef I, Bomzon A (2004) Cholemic transgenic mice: a novel animal model to investigate the effects of bile acids. J Pharmacol Toxicol Methods 50:231-235

57. Luttringer O, Theil FP, Lave T, Wernli-Kuratli K, Guentert TW, de Saizieu A (2002) Influence of isolation procedure, extracellular matrix and dexamethasone on the regulation of membrane transporters gene expression in rat hepatocytes. Biochem Pharmacol 64:1637-1650

58. Ma K, Saha PK, Chan L, Moore DD (2006) Farnesoid X receptor is essential for normal glucose homeostasis. J Clin Invest 116:1102-1109

59. Marschall HU, Wagner M, Zollner G, Fickert P, Diczfalusy U, Gumhold J, Silbert D, Fuchsbichler A, Benthin L, Grundstrom R, Gustafsson U, Sahlin S, Einarsson C, Trauner M (2005) Complementary stimulation of hepatobiliary transport and detoxification systems by rifampicin and ursodeoxycholic acid in humans. Gastroenterology 129:476-485

60. Meier PJ (2002) Canalicular bile formation: beyond single transporter functions. J Hepatol 37:272-273
61. Meier PJ, Stieger B (2002) Bile salt transporters. Annu Rev Physiol 64:635-661

62. Meier Y, Cavallaro M, Roos M, Pauli-Magnus C, Folkers G, Meier PJ, Fattinger K (2005) Incidence of drug-induced liver injury in medical inpatients. Eur J Clin Pharmacol 61:135-143

63. Meier Y, Pauli-Magnus C, Zanger UM, Klein K, Schaeffeler E, Nussler AK, Nussler N, Eichelbaum M, Meier PJ, Stieger B (2006) Interindividual variability of canalicular ATP-bindingcassette (ABC)-transporter expression in human liver. Hepatology 44:62-74

64. Meyers RL, Book LS, O'Gorman MA, Jackson WD, Black RE, Johnson DG, Matlak ME (2003) High-dose steroids, ursodeoxycholic acid, and chronic intravenous antibiotics improve bile flow after Kasai procedure in infants with biliary atresia. J Pediatr Surg 38:406-411

65. Misra S, Ujhazy P, Varticovski L, Arias IM (1999) Phosphoinositide 3-kinase lipid products regulate ATP-dependent transport by sister of P-glycoprotein and multidrug resistance associated protein 2 in bile canalicular membrane vesicles. Proc Natl Acad Sci USA 96:5814-5819

66. Misra S, Varticovski L, Arias IM (2003) Mechanisms by which cAMP increases bile acid secretion in rat liver and canalicular membrane vesicles. Am J Physiol Gastrointest Liver Physiol 285:G316-G324

67. Moseley RH (1997) Sepsis-associated cholestasis. Gastroenterology 112:302-306

68. Muhlfeld A, Kubitz R, Dransfeld O, Haussinger D, Wettstein M (2003) Taurine supplementation induces multidrug resistance protein 2 and bile salt export pump expression in rats and prevents endotoxin-induced cholestasis. Arch Biochem Biophys 413:32-40

69. Noe J, Hagenbuch B, Meier PJ, St-Pierre MV (2001) Characterization of the mouse bile salt export pump overexpressed in the baculovirus system. Hepatology 33:1223-1231

70. Noe J, Kullak-Ublick GA, Jochum W, Stieger B, Kerb R, Haberl M, Mullhaupt B, Meier PJ, Pauli-Magnus C (2005) Impaired expression and function of the bile salt export pump due to three novel ABCB11 mutations in intrahepatic cholestasis. J Hepatol 43:536-543

71. Noe J, Meier PJ, St Pierre MV (2001) Functional characterization of the phosphorylation of the bile salt export pump by protein kinase C. Hepatology 34:255A

72. Noe J, Stieger B, Meier PJ (2002) Functional expression of the canalicular bile salt export pump of human liver. Gastroenterology 123:1659-1666

73. Ortiz DF, Moseley J, Calderon G, Swift AL, Li S, Arias IM (2004) Identification of HAX-1 as a protein that binds bile salt export protein and regulates its abundance in the apical membrane of Madin-Darby canine kidney cells. J Biol Chem 279:32761-32770

74. Ortiz DF, St Pierre MV, Abdulmessih A, Arias IM (1997) A yeast ATP-binding cassette-type protein mediating ATP-dependent bile acid transport. J Biol Chem 272:15358-15365

75. Oude Elferink RP, Paulusma CC, Groen AK (2006) Hepatocanalicular transport defects: pathophysiologic mechanisms of rare diseases. Gastroenterology 130:908-925

76. Pauli-Magnus C, Kerb R, Fattinger K, Lang T, Anwald B, Kullak-Ublick GA, Beuers U, Meier PJ (2004) BSEP and MDR3 haplotype structure in healthy Caucasians, primary biliary cirrhosis and primary sclerosing cholangitis. Hepatology 39:779-791

77. Pauli-Magnus C, Meier PJ (2005) Hepatocellular transporters and cholestasis. J Clin Gastroenterol 39:S103-S110

78. Pauli-Magnus C, Stieger B, Meier Y, Kullak Ublick GA, Meier PJ (2005) Enterohepatic transport of bile salts and genetics of cholestasis. J Hepatol 43:342-357 
79. Paumgartner G, Beuers U (2004) Mechanisms of action and therapeutic efficacy of ursodeoxycholic acid in cholestatic liver disease. Clin Liver Dis 8:67-81

80. Perwaiz S, Forrest D, Mignault D, Tuchweber B, Phillip MJ, Wang R, Ling V, Yousef IM (2003) Appearance of atypical 3 alpha, 6 beta, 7 beta, 12 alpha-tetrahydroxy- 5 beta-cholan-24-oic acid in spgp knockout mice. J Lipid Res 44:494-502

81. Plass JR, Mol O, Heegsma J, Geuken M, de Bruin J, Elling G, Muller M, Faber KN, Jansen PL (2004) A progressive familial intrahepatic cholestasis type 2 mutation causes an unstable, temperature-sensitive bile salt export pump. J Hepatol 40:24-30

82. Rippin SJ, Hagenbuch B, Meier PJ, Stieger B (2001) Cholestatic expression pattern of sinusoidal and canalicular organic anion transport systems in primary cultured rat hepatocytes. Hepatology 33:776-782

83. Schliess F, Kurz AK, vom Dahl S, Haussinger D (1997) Mitogen-activated protein kinases mediate the stimulation of bile acid secretion by tauroursodeoxycholate in rat liver. Gastroenterology 113:1306-1314

84. Shoda J, Kano M, Oda K, Kamiya J, Nimura Y, Suzuki H, Sugiyama Y, Miyazaki H, Todoroki T, Stengelin S, Kramer W, Matsuzaki Y, Tanaka N (2001) The expression levels of plasma membrane transporters in the cholestatic liver of patients undergoing biliary drainage and their association with the impairment of biliary secretory function. Am J Gastroenterol 96:3368-3378

85. Sinal CJ, Tohkin M, Miyata M, Ward JM, Lambert G, Gonzalez FJ (2000) Targeted disruption of the nuclear receptor FXR/BAR impairs bile acid and lipid homeostasis. Cell 102:731-744

86. Stieger B, Fattinger K, Madon J, Kullak Ublick GA, Meier PJ (2000) Drug- and estrogen-induced cholestasis through inhibition of the hepatocellular bile salt export pump (Bsep) of rat liver. Gastroenterology 118:422-430

87. Stieger B, Meier PJ (1998) Bile acid and xenobiotic transporters in liver. Curr Opin Cell Biol 10:462-467

88. Strautnieks SS, Bull LN, Knisely AS, Kocoshis SA, Dahl N, Arnell H, Sokal E, Dahan K, Childs S, Ling V, Tanner MS, Kagalwalla AF, Nemeth A, Pawlowska J, Baker A, Mieli-Vergani G, Freimer NB, Gardiner RM, Thompson RJ (1998) A gene encoding a liver-specific $\mathrm{ABC}$ transporter is mutated in progressive familial intrahepatic cholestasis. Nat Genet 20:233-238

89. Tomer G, Ananthanarayanan M, Weymann A, Balasubramanian N, Suchy FJ (2003) Differential developmental regulation of rat liver canalicular membrane transporters bsep and mrp2. Pediatr Res 53:288-294

90. Torok M, Gutmann H, Fricker G, Drewe J (1999) Sister of Pglycoprotein expression in different tissues. Biochem Pharmacol 57:833-835

91. Trauner M, Boyer JL (2003) Bile salt transporters: molecular characterization, function, and regulation. Physiol Rev 83:633-671

92. Turncliff RZ, Tian X, Brouwer KL (2006) Effect of culture conditions on the expression and function of Bsep, Mrp2, and Mdr1a/b in sandwich-cultured rat hepatocytes. Biochem Pharmacol 71:1520-1529

93. Vallejo M, Briz O, Serrano MA, Monte MJ, Marin JJ (2006) Potential role of trans-inhibition of the bile salt export pump by progesterone metabolites in the etiopathogenesis of intrahepatic cholestasis of pregnancy. J Hepatol 44:1150-1157

94. Vos TA, Hooiveld GJ, Koning H, Childs S, Meijer DK, Moshage H, Jansen PL, Muller M (1998) Up-regulation of the multidrug resistance genes, Mrp1 and Mdr1b, and down-regulation of the organic anion transporter, Mrp2, and the bile salt transporter, Spgp, in endotoxemic rat liver. Hepatology 28:1637-1644

95. Wakabayashi Y, Lippincott-Schwartz J, Arias IM (2004) Intracellular trafficking of bile salt export pump (ABCB11) in polarized hepatic cells: constitutive cycling between the canalicular membrane and rab11-positive endosomes. Mol Biol Cell 15:3485-3496

96. Wang L, Boyer JL (2004) The maintenance and generation of membrane polarity in hepatocytes. Hepatology 39:892-899

97. Wang L, Soroka CJ, Boyer JL (2002) The role of bile salt export pump mutations in progressive familial intrahepatic cholestasis type II. J Clin Invest 110:965-972

98. Wang R, Lam P, Liu L, Forrest D, Yousef IM, Mignault D, Phillips MJ, Ling V (2003) Severe cholestasis induced by cholic acid feeding in knockout mice of sister of P-glycoprotein. Hepatology 38:1489-1499

99. Wang R, Salem M, Yousef IM, Tuchweber B, Lam P, Childs SJ, Helgason CD, Ackerley C, Phillips MJ, Ling V (2001) Targeted inactivation of sister of P-glycoprotein gene (spgp) in mice results in nonprogressive but persistent intrahepatic cholestasis. Proc Natl Acad Sci USA 98:2011-2016

100. Warskulat U, Kubitz R, Wettstein M, Stieger B, Meier PJ, Haussinger D (1999) Regulation of bile salt export pump mRNA levels by dexamethasone and osmolarity in cultured rat hepatocytes. Biol Chem 380:1273-1279

101. Watanabe M, Houten SM, Mataki C, Christoffolete MA, Kim BW, Sato H, Messaddeq N, Harney JW, Ezaki O, Kodama T, Schoonjans K, Bianco AC, Auwerx J (2006) Bile acids induce energy expenditure by promoting intracellular thyroid hormone activation. Nature 439:484-489

102. Wolters H, Elzinga BM, Baller JF, Boverhof R, Schwarz M, Stieger B, Verkade HJ, Kuipers F (2002) Effects of bile salt flux variations on the expression of hepatic bile salt transporters in vivo in mice. J Hepatol 37:556-563

103. Zinchuk V, Zinchuk O, Okada T (2005) Experimental LPSinduced cholestasis alters subcellular distribution and affects colocalization of Mrp2 and Bsep proteins: a quantitative colocalization study. Microsc Res Tech 67:65-70

104. Zinchuk VS, Okada T, Akimaru K, Seguchi H (2002) Asynchronous expression and colocalization of Bsep and Mrp2 during development of rat liver. Am J Physiol Gastrointest Liver Physiol 282:G540-G548

105. Zollner G, Fickert P, Silbert D, Fuchsbichler A, Marschall HU, Zatloukal K, Denk H, Trauner M (2003) Adaptive changes in hepatobiliary transporter expression in primary biliary cirrhosis. J Hepatol 38:717-727

106. Zollner G, Fickert P, Zenz R, Fuchsbichler A, Stumptner C, Kenner L, Ferenci P, Stauber RE, Krejs GJ, Denk H, Zatloukal K, Trauner M (2001) Hepatobiliary transporter expression in percutaneous liver biopsies of patients with cholestatic liver diseases. Hepatology 33:633-646 